\title{
PENGGUNAAN MODEL PEMBELAJARAN SOMATIC, AUDITORY, VISUALIZATION, INTELLECTUALY (SAVI) DALAM PENINGKATAN HASIL BELAJAR IPA TENTANG ORGAN PENCERNAAN MANUSIA KELAS V SD NEGERI 3 DOROWATI TAHUN AJARAN 2020/2021
}

\author{
Rizki Isnaeni Putri ${ }^{1}$, Suhartono $^{2}$, Muhamad Chamdani ${ }^{3}$ \\ Universitas Sebelas Maret \\ rizkiisnaeniputri@student.uns.ac.id
}

\section{Article History}

accepted 30/8/2021

approved 30/9/2021

published 30/10/2021

\begin{abstract}
The objectives of the research were: (1) to describe the steps of SAVI model in improving natural science learning outcomes, (2) to increase natural science learning outcomes about human digestive system, and (3) to describe the obstacles and solutions in applying SAVI model in improving natural science learning outcomes about human digestive system. The collaborative classroom action research was conducted in two cycles. The subjects were the teacher and 10 students of fifth grade of SDN 3 Dorowati. Data collection techniques were observation, interviews, and tests. The data validity used triangulation of techniques and triangulation of sources. The data analysis included data reduction, data presentation, and conclusions. The results indicated that: (1) the steps of Somatic, Auditory, Visualization, Intellectual (SAVI) model were: (a) preparation stage, (b) delivery stage, (c) training stage, and (d) final stage; (2) the application SAVI model improved natural science learning outcomes about human digestive system to fifth grade students of SDN 3 Dorowati in academic year of 2020/2021; (3) the obstacles were that many students did not cooperate in group discussions and found difficulties in making concept maps. The solutions were that the teacher guided the students to have discussion properly and helped the students in making concept maps.

Keywords: Somatic, Auditory, Visualization, Intellectual (SAVI) model, learning outcomes, natural science
\end{abstract}

Abstrak: Penggunaan Model Pembelajaran Somatic, Auditory, Visualization, Intellectually (SAVI) dalam Peningkatan Pembelajaran IPA tentang Organ Pencernaan Manusia Kelas V SDN 3 Dorowati Tahun Ajaran 2020/2021. Tujuan penelitian ini yaitu: (1) mendeskripsikan langkah model pembelajaran SAVI dalam peningkatan hasil belajar IPA; (2) meningkatkan hasil belajar IPA tentang organ pencernaan manusia; (3) mendeskripsikan kendala dan solusi penerapan model pembelajaran SAVI dalam peningkatan hasil belajar IPA tentang organ pencernaan manusia. Penelitian Tindakan Kelas (PTK) ini dilaksanakan dalam dua siklus. Subjek penelitian ini adalah guru kelas dan 10 siswa kelas V SDN 3 Dorowati. Teknik pengumpulan data yang digunakan adalah observasi, wawancara, dan tes. Validitas data menggunakan triangulasi teknik dan sumber. Analisis data dilaksanakan melalui reduksi data, penyajian data, dan penarikan kesimpulan. Hasil penelitian ini menunjukkan bahwa: (1) langkah penggunaan model SAVI, yaitu: (a) tahap persiapan, (b) tahap penyampaian, (c) tahap pelatihan, dan (d) tahap penampilan hasil; (2) penggunaan model SAVI dapat meningkatkan hasil belajar IPA tentang organ pencernaan manusia siswa kelas V SDN 3 Dorowati tahun ajaran 2020/2021; (3) kendala dalam penelitian ini adalah masih banyak siswa yang kurang bekerjasama dalam diskusi kelompok dan kesulitan dalam membuat peta konsep. Solusi dari kendala tersebut yaitu guru membimbing siswa agar berdiskusi dengan benar, dan guru membantu siswa saat membuat peta konsep.

Kata kunci : Somatic, Auditory, Visualization, Intellectualy (SAVI), Hasil Belajar, IPA 


\section{PENDAHULUAN}

Kurikulum 2013 mengintegrasikan beberapa mata pelajaran dalam satu tema. Semua mata pelajaran disesuaikan dengan materi pembelajaran standar internasional terutama Matematika dan IImu Pengetahuan Alam (IPA). IPA adalah salah satu pembelajaran yang sangat penting. Hal ini dibuktikan dengan diberikannya pembelajaran IPA untuk semua jenjang pendidikan formal di Indonesia, mulai dari jenjang pendidikan dasar, menengah, hingga perguruan tinggi. Selain itu, alasan IPA dianggap penting karena IPA memuat ilmu-ilmu yang berkaitan dengan kehidupan sehari-hari. Meskipun pada Kurikulum 2013 mata pelajaran IPA diintegrasikan dengan tematik, akan tetapi tidak mengurangi porsi penting pokok pembahasan materi yang harus dipelajari di jenjang sekolah dasar.

IPA merupakan suatu ilmu yang membutuhkan pemahaman mengenai teori-teori, konsep-konsep dan fakta-fakta pada setiap isinya, IPA bukan hanya sebatas hafalan saja. Putra (2013: 51) menyatakan sains atau IPA adalah pengetahuan yang mempelajari, menjelaskan, serta menginvestigasi fenomena alam dengan segala aspeknya yang bersifat empiris. Maka dari itu dalam melaksanakan pembelajaran IPA sebaiknya sebagai guru haruslah kreatif dalam mendesain pembelajaran yang mampu melibatkan peserta didik agar lebih berpikir kritis, aktif, dan dapat menyelesaikan masalah sehari-hari.

Berdasarkan hasil observasi yang dilakukan peneliti terhadap siswa kelas V SD Negeri 3 Dorowati yang dilaksanakan pada hari Senin, tanggal 24 Agustus 2020 menunjukan bahwa dalam proses pembelajaran siswa kelas $V$ cenderung pasif, kurang termotivasi, dan tidak memperhatikan materi yang guru sampaikan sehingga berdampak pada hasil belajar siswa. Hal ini dikarenakan guru belum menggunakan model pembelajaran yang variatif dan berpusat pada siswa.

Uraian di atas didukung oleh hasil wawancara yang dilakukan peneliti terhadap guru kelas V SD Negeri 3 Dorowati yang dilaksanakan pada hari Sabtu, tanggal 22 Agustus 2020. Hasil wawancara menunjukan bahwa dalam pembelajaran IPA masih banyak siswa kelas $\mathrm{V}$ yang mendapat nilai di bawah KKM pada Penilaian Harian Tema 1. Hal ini dapat dilihat dari ketuntasan PH Tema 1 hanya sekitar $50 \%$ yang sebagian besar ketuntasan dibantu dengan remedial. Dari 20 siswa kelas V SD Negeri 3 Dorowati masih ada 10 siswa yang belum memenuhi KKM. Djamarah dan Zain (2013: 108) menyatakan apabila jumlah siswa yang mencapai taraf keberhasilan kurang dari $75 \%$ dari jumlah siswa yang mengikuti proses belajar, maka proses belajar mengajar berikutnya hendaknya bersifat perbaikan (remedial).

Berdasarkan hasil observasi dan wawancara di atas, alternatif pemecahan masalah yang dianggap sesuai untuk mengatasi permasalahan tersebut adalah diperlukan model pembelajaran yang variatif, berpusat pada siswa dan menumbuhkan motivasi siswa untuk belajar. Salah satu model pembelajaran yang dapat mengatasi masalah tersebut ialah model pembelajaran Somatic, Auditory, Visualization, Intellectualy (SAVI). Model pembelajaran Somatic, Auditory, Visualization, Intellectualy (SAVI) adalah model yang menggabungkan aktivitas fisik dan sehingga pembelajaran akan menyenangkan dan membuat siswa terlibat aktif dalam pembelajaran (Shoimin, 2014: 177). Hal tersebut sesuai dengan pendapat Anas dan Syafitri (2019: 39) bahwa model SAVI adalah model pembelajaran yang memanfaatkan semua pancaindera siswa dan pembelajaran dilakukan dengan menggabungkan aktivitas fisik dan intelektual sehingga suasana belajar akan menyenangkan, bermakna, dan membuat siswa termotivasi untuk aktif dalam belajar. Sardiman (Sholihah, 2016: 2) menyatakan bahwa motivasi belajar mempunyai peran penting dalam hal penumbuhan gairah dan semangat belajar. Siswa yang memiliki motivasi belajar tinggi memungkinkan hasil belajar yang tinggi pula.

Berdasarkan latar belakang di atas maka peneliti tertarik untuk mengadakan penelitian tindakan kelas yang bertujuan untuk: (1) mendeskripsikan langkah-langkah 
model pembelajaran Somatic, Auditory, Visualization, Intellectualy (SAVI) dalam peningkatan hasil belajar IPA; (2) meningkatkan hasil belajar IPA tentang organ pencernaan manusia; (3) mendeskripsikan kendala dan solusi penerapan model pembelajaran Somatic, Auditory, Visualization, Intellectualy (SAVI) dalam peningkatan hasil belajar IPA tentang organ pencernaan manusia pada siswa kelas V SD Negeri 3 Dorowati tahun ajaran 2020/2021.

\section{METODE}

Penelitian Tindakan Kelas (PTK) kolaboratif ini dilaksanakan di SD Negeri 3 Dorowati, Kecamatan Klirong, Kabupaten Kebumen. Waktu pelaksanaan pada semester I tahun ajaran 2020/2021. Akibat pandemi Covid-19 yang tidak mengizinkan siswa untuk berangkat sekolah dan berkumpul dengan jumlah yang banyak, maka peneliti memutuskan mengambil subjek penelitian ini sebanyak 10 siswa dari 20 siswa yang terdiri dari 1 siswa perempuan dan 9 siswa laki-laki, siswa yang menjadi subjek penelitian adalah siswa yang belum tuntas pada penilaian harian 1 tema 1 . Teknik pengumpulan data terdiri dari nontes dan tes. Teknik uji validitas data menggunakan triangulasi sumber yang berasal dari guru dan siswa serta triangulasi teknik yang digunakan yaitu wawancara, observasi dan tes. Teknik analisis data yang digunakan dalam penelitian ini yaitu reduksi data, penyajian data, dan penarikan kesimpulan sesuai model analisis data menurut Miles dan Huberman (Sugiyono, 2015: 247-253). Indikator kinerja penelitian yaitu apabila terdapat peningkatan pembelajaran IPA tentang organ pencernaan manusia melalui penerapan model Somatic, Auditory, Visualization, dan Intelectually (SAVI) mencapai $85 \%$. Penelitian tindakan kelas ini dilaksanakan dalam tiga siklus. Setiap siklus memuat empat tahap kegiatan yaitu perencanaan, pelaksanaan tindakan, pengamatan, dan refleksi.

\section{HASIL DAN PEMBAHASAN}

Penggunaan model Somatic, Auditory, Visualization, Intellectualy (SAVI) dalam peningkatan hasil belajar IPA siswa kelas V SD Negeri 3 Dorowati dilakukan dalam dua siklus. Masing-masing siklus terdiri dari dua pertemuan dengan alokasi waktu 70 menit setiap pertemuan.

Model Somatic, Auditory, Visualization, Intellectualy (SAVI) adalah model pembelajaran yang menekankan bahwa belajar haruslah memanfaatkan semua alat indra yang dimiliki siswa (Shoimin, 2014: 177). Hal ini sejalan dengan pendapat Samosir, Sugiharto, dan Siman (2017: 84) bahwa pembelajaran SAVI adalah pembelajaran proses yang menggabungkan aktivitas fisik dan intelektual yang melibatkan semua pancaindera. Dalam model SAVI, fisik gerakan mengembangkan proses mental. Bagian otak manusia yang terlibat dalam gerakan tubuh (konten motorik) adalah di sisi otak digunakan untuk berpikir dan menyelesaikan masalah. Melibatkan tubuh dalam pembelajaran biasanya meningkatkan integrasi.

Adapun langkah-langkah penerapan model Somatic, Auditory, Visualization, Intelectually (SAVI) untuk meningkatkan hasil belajar IPA tentang organ pencernaan manusia pada siswa kelas V SD Negeri 3 Dorowati yaitu: (a) tahap persiapan, (b) tahap penyampaian, (c) tahap pelatihan, dan (d) tahap penampilan hasil. Langkahlangkah yang digunakan oleh peneliti mengacu pada langkah-langkah yang dikemukakan oleh Meirer (Rusman, 2012: 373-374) kemudian peneliti menyimpulkan menjadi langkah-langkah yang disebutkan di atas.

Penggunaan model Somatic, Auditory, Visualization, Intellectualy (SAVI) dalam peningkatan hasil belajar IPA tentang organ pencernaan manusia mengalami berbagai perbaikan pada proses pembelajaran untuk mencapai hasil yang optimal. Perbandingan antarsiklus hasil observasi dapat dilihat pada tabel 1 berikut. 
Tabel 1. Analisis Hasil Observasi Penggunaan Model Somatic, Auditory, Visualization, Intellectualy (SAVI) dalam peningkatan hasil belajar IPA tentang organ pencernaan manusia Siklus I dan II.

\begin{tabular}{lccc}
\hline \multicolumn{2}{c}{ Sumber Data } & \multicolumn{3}{c}{ Siklus } \\
\cline { 2 - 4 } & & I & II \\
\hline Guru & Persentase (\%) & 82.48 & 91.51 \\
\hline Siswa & Persentase (\%) & 79,82 & 90.35 \\
\hline
\end{tabular}

Berdasarkan Tabel I di atas, dapat diketahui bahwa pengamatan terhadap guru pada siklus I dan siklus II mengalami peningkatan sebesar $9,03 \%$ dari $82,48 \%$ menjadi $91,51 \%$. Pengamatan terhadap siswa juga mengalami peningkatan. Siklus I ke siklus II mengalami peningkatan sebesar $10,53 \%$ dari $79,82 \%$ menjadi $90,35 \%$.

Tabel 2. Perbandingan Antarsiklus Hasil Belajar Siswa Siklus I dan II.

\begin{tabular}{lcc}
\hline & \multicolumn{2}{c}{ Siklus } \\
\cline { 2 - 3 } & I & II \\
\hline Tuntas & 65 & 85 \\
Belum Tuntas & 35 & 15 \\
\hline
\end{tabular}

Berdasarkan tabel di atas, dapat diketahui bahwa rata-rata ketuntasan hasil belajar siswa pada siklus I dan siklus II selalu mengalami peningkatan. Persentase rata-rata ketuntasan siswa pada siklus II sebesar $85 \%$ sudah mencapai target indikator kinerja penelitian yaitu $85 \%$.

Uraian mengenai langkah-langkah model Somatic, Auditory, Visualization, Intelectually (SAVI) dalam pembelajaran sebagai berikut:

1. Tahap Persiapan

Pada tahap persiapan guru telah menyiapkan kondisi fisik dan psikis siswa dengan baik, guru telah menyampaikan tujuan pembelajaran dengan bahasa yang baik dan mudah dipahami. Erayati, Thomas, dan Syarifudin (2014: 8) menyatakan bahwa penyampaian tujuan pembelajaran membantu pikiran siswa agar terarah pada pembelajaran dan siswa akan mempersiapkan diri untuk mengikuti proses pembelajaran berikutnya. Setelah penyampaian tujuan pembelajaran guru melakukan motivasi kepada siswa agar siswa antusias dan semangat dalam belajar, hal ini sesuai dengan pendapat Fahyuni dan Istikomah (2016: 106) bahwa kegiatan memotivasi siswa dapat menumbuhkan gairah dan perfoma siswa dalam belajar dan melahirkan prestasi.

2. Tahab Penyampaian

Pada tahap ini guru telah menyampaiakan materi secara umum dengan cara yang vairiatif dan menggabungkan kegiatan-kegiatan pembelajaran yang memenuhi unsur SAVI yaitu somatic, auditory, visual, dan intelektual. Kegiatan pembelajaran yang variatif dan menggabungkan unsur-unsur SAVI membuat pembelajaran lebih menarik dan membuat siswa tidak cepat bosan dalam belajar. Hal ini sejalan dengan pendapat Artikawati (Aliffiani, Syafrina, \& Husin, 2018: 26) yang menyatakan bahwa viariasi kegiatan pembelajaran memberikan pengaruh positif pada perhatian dan keaktifan siswa, membuat siswa lebih reseptif terhadap pembelajaran.

3. Tahap Pelatihan

Pada tahap pelatihan guru membagi siswa menjadi dua kelompok, masingmasing kelompok beranggotakan 5 anak. Tujuan dari pembentukan kelompok tersebut adalah agar menumbuhkan rasa tanggungjawab, kerjasama, dan rasa sosial siswa. Hal ini sejalan dengan pendapat Hadi dan Noor (2013: 62) bahwa pembentukan kelompok dapat meningkatkan kemampuan bekerjasama, 
bersosialisasi, berkomunikasi, dan prestasi belajar siswa. Setelah bekerja kelompok guru membagikan LKS kepada masing-masing kelompok. Umbaryati (2016: 221) menyatakan bahwa Lembar Kerja Siswa (LKS) merupakan salah satu sarana untuk membantu dan mempermudah dalam kegiatan belajar mengajar sehingga akan terbentuk interaksi yang efektif antara peserta didik, sehingga dapat meningkatkan aktivitas peserta didik dalam peningkatan prestasi belajar. Pengerjaan LKS secara kelompok telah memenuhi unsur-unsur SAVI yaitu auditory (belajar dengan berbicara dan mendengar), visualization (belajar dengan mengamati), dan intellectually (belajar memecahkan masalah). Setelah masingmasing kelompok berdiskusi mengerjakan LKS guru memerintahkan siswa untuk membuat peta konsep pembelajaran yang sudah dilaksanakan, tujuan pembuatan peta konsep menurut pendapat Darusman (2014: 168) yaitu peta konsep berfungsi untuk memudahkan siswa mencatat hal-hal penting pokok bahasan materi pembelajaran yang sudah dilaksanakan. Kegiatan pembuatan peta konsep adalah kegiatan yang memenuhi unsur SAVI somatic (belajar dengan melakukan), visualization (belajar denganmengamati dan menggambarkan), dan intellectually (belajar memecahkan masalah). Setelah kegiatan diskusi selesai guru memotivasi siswa agar percaya diri dalam melakukan presentasi hasil diskusi dan agar siswa berani memberikan tanggapan kepada kelompok lain, melakukan presentasi sudah memenuhi unsur SAVI somatic (belajar dengan melakukan) dan auditory (belajar dengan mendengar dan berbicara). Kegiatan motivasi yang diakukan guru sangat bermanfaat untuk mendorong rasa percaya diri siswa sesuai dengan pendapat Slavin (Nurhasanah \& Sobandi, 2018: 191) bahwa siswa yang termotivasi akan lebih mudah diarahkan, diberi penugasan, cenderung memiliki rasa ingin tahu yang besar, serta aktif dalam mengikuti pembelajaran.

4. Tahap Penampilan Hasil

Pada tahap penampilan hasil guru menanyakan kepada siswa tentang materi-materi yang belum dipahami, dan guru memerintahkan siswa untuk menuliskan rangkuman materi yang sudah dipelajari, setelah kegiatan merangkum selesai guru melakukan evaluasi dengan pembagian soal kepada masing-masing siswa, setelah melakukan evaluasi guru menyampaiakan pesan moral, menyampaiakan pembelajaran berikutnya, dan menutup dengan salam. Hal ini sejalan dengan pendapat Mulyasa (Sani, 2016) bahwa kegiatan menutup pembelajaran dapat dilakukan dengan cara menarik kesimpulan pembelajaran yang sudah dipelajari, guru memberikan beberapa pertanyaan untuk mengetahui ketercapaian siswa, guru memberikan tugas-tugas pendalaman materi dan guru melakukan evaluasi berupa post test.

Peningkatan hasil belajar IPA tentang organ pencernaan manusia berhasil jika persentase hasil belajar IPA tentang organ pencernaan manusia mencapai indikator kinerja penelitian sebesar $85 \%$. Hasil observasi pada siklus I rata-rata persentase hasil belajar IPA tentang organ pencernaan manusia mencaoai target sebesar $65 \%$ dan siklus II meningkat menjadi $85 \%$. Hal ini sejalan dengan pendapat Shoimin (2016: 182) yeng menyatakan bahwa salah satu kelebihan dari penerapan model Somatic, Auditory, Visualization, Intelectually (SAVI) yaitu membuat suasana proses pembelajaran menarik dan menyenangkan sehingga menumbuhkan rasa semangat dan minat belajar siswa. Hindi, Berndoff, dan Ainley (Nurhasanah \& Sobandi, 2016: 130) menyatakan bahwa minat memberikan pengaruh positif terhadap pembelajaran akademik, domain pengetahuan dan bidang studi tertentu bagi individu. Hidi dan Reninger meyakini bahwa minat mempengaruhi tiga aspek penting dalam pengetahuan seseorang yaitu perhatian, tujuan, dan tingkat pembelajaran (Nurhasanah \& Sobandi, 2016: 130). Berdasarkan pembahasan tersebut dapat disimpulkan bahwa penerapan model Somatic, Auditory, Visualization, Intelectually (SAVI) dapat meningkatkan hasil 
belajar IPA tentang organ pencernaan manusia di kelas V SDN 3 Dorowati tahun ajaran 2020/2021.

Berdasarkan hasil observasi langkah model Somatic, Auditory, Visualization, Intelectually (SAVI) pada peningkatan hasil belajar IPA ditemukan beberapa kendala yaitu masih banyak siswa yang kurang bekerjasama dalam diskusi kelompok dan kesulitan dalam membuat peta konsep. Adapun solusi dari kendala tersebut yaitu guru membimbing siswa agar berdiskusi dengan benar dan guru membantu siswa dalam pembuatan peta konsep.

\section{SIMPULAN}

Berdasarkan hasil penelitian dan pembahasan yang telah diuraikan, maka simpulan dari penelitian ini adalah: (1) langkah penerapan model Somatic, Auditory, Visualization, Intelectually (SAVI) untuk meningkatkan hasil belajar IPA tentang organ pencernaan manusia pada siswa kelas V SD Negeri 3 Dorowati yaitu: (a) tahap persiapan, (b) tahap penyampaian, (c) tahap pelatihan, dan (d) tahap penampilan hasil; (2) penerapan model Somatic, Auditory, Visualization, Intelectually (SAVI) dapat meningkatkan hasil belajar IPA tentang organ pencernaan manusia dari persentase ketuntasan siswa yaitu 65\% pada siklus I, dan $85 \%$ pada siklus II; (3) kendala penerapan model Somatic, Auditory, Visualization, Intelectually (SAVI) untuk meningkatkan hasil belajar IPA tentang organ pencernaan manusia salah satunya adalah masih banyak siswa yang kurang bekerjasama dalam diskusi kelompok dan kesulitan dalam membuat peta konsep. Adapun solusi dari kendala tersebut yaitu guru membimbing siswa agar berdiskusi dengan benar dan guru membantu siswa dalam pembuatan peta konsep.

Berdasarkan simpulan yang telah dipaparkan, peneliti memberikan beberapa saran: (1) bagi guru, hendaknya guru menguasai langkah-langkah model pembelajaran SAVI dan menciptakan pembelajaran yang menyenangkan dan melibatkan semua pancaindera siswa agar pembelajaran menarik dan tidak membosankan; (2) bagi siswa, siswa harus meningkatkan kerjasama dan berpikir kritis dalam melaksanakan diskusi, dan siswa harus meningkatkan keberanian untuk melakukan presentasi; (3) bagi sekolah, sekolah hendaknya menyediakan sarana dan prasarana pembelajaran yang lengkap untuk mendukung guru berinovasi dalam menerapkan berbagai macam model pembelajaran; (4) bagi peneliti lain, peneliti lain sebaiknya membuat kegiatan pembelajaran yang kreatif dan inovatif sesuai dengan perkembangan ilmu pengetahuan dan teknologi.

\section{DAFTAR PUSTAKA}

Aliffiani, H.S., Syafrina, A., \& Husin, M. (2018). Kemampuan Guru dalam Menerapkan Keterampilan Variasi Stimulus di SD Negeri 71 Banda Aceh. Jurnal IImiah Pendidikan Guru Sekolah Dasar, 3 (2), 24-34

Anas, N., \& Syafitri, K. (2019). Pengaruh Model SAVI (Somatic, Auditory, Visualization, Intellectualy) Terhadap Hasil Belajar. NIZHAMIYAH, 9(1)

Darusman, R. (2014). Penerapan metode mind mapping (peta pikiran) untuk meningkatkan kemampuan berpikir kreatif matematik siswa SMP. Infinity Journal, 3(2), 164-173

Djamarah, S.B \& Zain, A. (2013). Strategi Belajar Mengajar. Jakarta: Rineka Cipta.

Erayati, T., Thomas, Y., \& Syahrudin, H. (2014). Pelaksanaan Kegiatan Belajar Mengajar oleh Guru pada Mata Pelajaran Ekonomi Kelas XI IPS 1 di SMA. Jurnal Pendidikan Ekonomi, 2 (1), 1-12

Fahyuni, E. F., \& Istikomah, I. (2016). Psikologi Belajar \& Mengajar (kunci sukses guru dalam interaksi edukatif). 
Hadi, S.G. \& Noor, A.J. (2013). Keefektifan Kelompok Belajar Siswa Berdasarkan Sosiometri dalam Menyelesaikan Soal Cerita Matematika di SMP. Jurnal pendidikan Matematika, 1 (1), 60-67

Nurhasanah, S., \& Sobandi, A. (2016). Minat belajar sebagai determinan hasil belajar siswa. Jurnal Pendidikan Manajemen Perkantoran (JPManper), 1(1), 128-135

Putra, S.R. (2013). Desain Belajar Mengajar Kreatif Berbasis SAINS. Yogjakarta:DIVA Press

Rusman. (2012). Model-model Pembelajaran Mengembangkan Profesionalisme Guru. Depok:Raja Grafindo

Samosir, R., Sugiharto., \& Siman. (2017). Influence Of Somatic, Auditory, Visual, Intelectual Approach (SAVI) and Learning Motivation To Students Social Studies Results Of Grade Iv Of 060809 Public Elementary School Medan Denai Academic Year 2016/2017. IOSR Journal of Research \& Method in Education (IOSR-JRME) e-ISSN: 2320-7388,p-ISSN: 2320-737X Volume 7, Issue 5 Ver. VII (Sep. - Oct. 2017), PP 83-86

Sani, M. (2016). Kegiatan Menutup Pelajaran. Journal of Accounting and Business Education, 1(3)

Shoimin, A. (2014). 68 Model Pembelajaran Inovatif dalam Kurikulum 2013. Yogyakarta:Ar-Ruzz Media

Sholihah, A. (2016). Analisis Pengaruh Motivasi Belajar dan Lingkungan Belajar terhadap Hasil Belajar. Jurnal Pendidikan Ekonomi (JUPE). 4 (3), 2016, 1-5.

Sugiyono. (2015). Metode Penelitian Pendidikan (Pendekatan Kuantitatif, Kualitatif, dan $R \& D)$. Bandung:Alfabeta

Umbaryati, U. (2016, February). Pentingnya LKPD pada Pendekatan Scientific Pembelajaran Matematika. In PRISMA, Prosiding Seminar Nasional Matematika (pp. 217-225). 